\title{
Efektifitas Aver Viewer dalam Memantau Kemacetan Lalu Lintas di Kota Batu
}

\author{
Miranda Rista Ilhami ${ }^{1}$, Farah Fadillah Anugrah Santaufanny ${ }^{2}$, \\ Rossa Sinambella ${ }^{3}$ \\ ${ }^{1}$ Universitas Muhammadiyah Malang, Indonesia \\ ${ }^{2}$ Universitas Muhammadiyah Malang, Indonesia \\ ${ }^{3}$ Universitas Muhammadiyah Malang, Indonesia \\ Email: mirandaristailhami@gmail.com ${ }^{1}$, farahfadillah1999@gmail.com² ${ }_{2}$ \\ rossasinambella02707@gmail.com ${ }^{3}$
}

\begin{abstract}
ABSTRAK
Sebagai Kota Wisata, kemacetan lalu lintas di Kota Batu terus mengalami peningakatan. Hal tersebut mendorong Dinas Perhubungan Kota Batu untuk menciptakan inovasi dalam memberikan kemudahan layanan kepada para pengguna jalan. Seiring dengan kemajuan teknologi komunikasi dan informasi Dinas Perhubungan Kota Batu meluncurkan sebuah aplikasi dengan nama Aver Viewer. Tujuan penelitian ini adalah untuk mengetahui efektivitas Aver Viewer dalam memantau kemacetan lalu lintas di Kota Batu dan apakah masyarakat Kota Batu telah mengetahui adanya aplikasi ini. Efektivitas merupakan tolak ukur keberhasilan dalam pencapaian tujuan-tujuan yang telah ditentukan. Tujuan dari dibuatnya aplikasi Aver Viewer dinilai sudah tercapai, karena adanya aplikasi ini mempermudah masyarakat dalam memantau kemacetan dan mencari jalur alternatif untuk dilewati. Penelitian ini menggunakan metode penelitian deskriptif dengan pendekatan kualitatif. Teknik pengumpulan data yang digunakan yaitu angket (kuesioner) dan wawancara langsung kepada Dinas Perhubungan Kota Batu serta masyarakat. Hasil dari penelitian ini adalah Aver Viewer dinilai cukup efektif dalam memantau kemacetan di Kota Batu, dengan danya aplikasi ini dapat mempermudah pengguna jalan untuk memantau keadaan lalu lintas tanpa harus datang langsung ke lapangan. Namun kurangnya sosialisasi yang dilakukan Dinas Perhubungan tentang aplikasi Aver Viewer ini menyebabkan kurangnya masyarakat yang mengetahui adanya aplikasi ini.
\end{abstract}

Kata Kunci: Kemacetan, Efektivitas, Aver Viewer, Sosialisasi

\section{ABSTRACT}

As a Tourism City, traffic congestion in Batu City continues to experience an increase. This encourages the Batu City Transportation Agency to create innovations in providing ease of service to road users. Along with advances in information and communication technology, the City of Batu Transportation Agency launched an application called Aver Viewer. The purpose of this study is to determine the effectiveness of Aver Viewer in monitoring traffic congestion in Kota Batu and whether the people of Kota Batu already know of this application. Effectiveness is a measure of success in achieving predetermined goals. The 
purpose of making the Aver Viewer application is considered to have been achieved, because this application makes it easier for the public to monitor congestion and find alternative routes to pass. This research uses descriptive research method with a qualitative approach. Data collection techniques used were questionnaire (questionnaire) and direct interviews to the Batu City Transportation Department and the community. The results of this study are that Aver Viewer is considered to be quite effective in monitoring traffic congestion in Batu City, with this application, it can facilitate road users to monitor traffic conditions without having to come directly to the field. But the lack of socialization carried out by the Department of Transportation about the Aver Viewer application caused the lack of people who knew of this application.

Keywords: Congestion, Effectiveness, Aver Viewer, Socialization

\section{PENDAHULUAN}

Seiring

dengan

berkembangnya teknologi informasi

yang semakin modern menyebabkan banyak perubahan di dalam segala aspek kehidupan. Perubahan tersebut juga membuat pemerintah pusat maupun pemerintah daerah di Indonesia dituntut untuk mengikuti perkembangan teknologi. Dengan adanya perkembangan teknologi ini diharapkan pemerintah dapat memberikan pelayanan publik secara optimal. Terwujudnya pelayanan publik yang optimal merupakan salah satu harapan bagi setiap lembaga pelayanan publik dan menjadi salah satu langkah strategis dalam rangka meningkatkan akses dan mutu layanan kepada masyarakat. Penyempurnaan dalam sistem pelayanan publik terus-menerus dilakukan oleh pemerintah untuk meningkatkan pengelolaan terhadap pelayanan publik, salah satunya adalah yang dilakukan oleh Dinas Perhubungan Kota Batu dalam meningkatkan kualitas pelayanan publik.

Kota Batu merupakan sebuah kota yang terletak di Provinsi Jawa Timur. Kota Batu adalah salah satu kota yang dikenal sebagai kota wisata terkemuka di Indonesia karena potensi keindahan alam yang sangat luar biasa. Oleh karena itu Kota Batu sering dijadikan tempat berlibur bagi para wisatawan lokal maupun mancanegara. Sebagai salah satu Kota Wisata yang terkenal di Indonesia, tak jarang Kota Batu sering mengalami kemacetan. Dengan adanya permasalahan kemacetan ini, Dinas Perhubungan Kota Batu dituntut untuk melakukan terobosan terbaru (inovasi) untuk mempermudah dalam memantau dan menyelesaikan permasalah kemacetan di Kota Batu sesuai dengan Peraturan Walikota Batu Nomor 82 Tahun 2016 Tentang Kedudukan, Susunan Organisasi, Uraian Tugas dan Fungsi, Serta Tata Kerja Dinas Perhubungan Kota Batu 
dalam BAB III Uraian Tugas dan Fungsi Bagian Kedua Bidang Lalu Lintas Pasal 6 yang menyatakan bahhwa bidang lalu lintas memiliki tugas merumuskan dan melaksanakan kebijakan teknis di bidang manajemen dan rekayasa lalu lintas serta pembinaan keselamatan.

Dengan adanya tuntutan dari masyarakat serta Peraturan Walikota Batu Nomor 82 Tahun 2016 tersebut, Dinas Perhubungan Kota Batu membuat inovasi baru dalam mempermudah memantau kemacetan lalu lintas di Kota Batu dengan cara membuat Aplikasi yang bernama Aver Viewer. Aplikasi Aver Viewer ini digunakan untuk menghindari kemacetan dan dapat digunakan untuk mencari solusi atau jalan alternatif yang bisa dilewati. Dengan adanya aplikasi Aver Viewer wisatawan maupun masyarakat bisa memantau keadaan lalu lintas di sejumlah titik di Kota Batu.

Peluncuran aplikasi Aver Viewer ini dilakukan oleh Dinas Perhubungan Kota Batu pada tahun 2013. Aplikasi Aver Viewer ini digunakan oleh Dinas Perhubungan yang bekerjasama langsung dengan pihak kepolisian lalu lintas untuk memantau kemacetan lalu lintas yang terjadi di Kota Batu. Selain untuk memantau kemacetan, CCTV yang terdapat di aplikasi Aver Viewer ini juga dapat digunakan untuk mengantisipasi jika ada kecelakaan, tindak kriminal serta mengungkap peristiwa kejahatan. Sehingga adanya aplikasi Aver Viewer tidak hanya memberikan kemudahan kepada masyarakat tetapi juga memberikan kemudahan kepada Dinas Perhubungan dan aparat kepolisian.

Tabel. 1 Jumlah Kunjungan

Wisatawan Berdasarka Tempat Wisata dan Wisata Oleh-oleh di Kota Batu

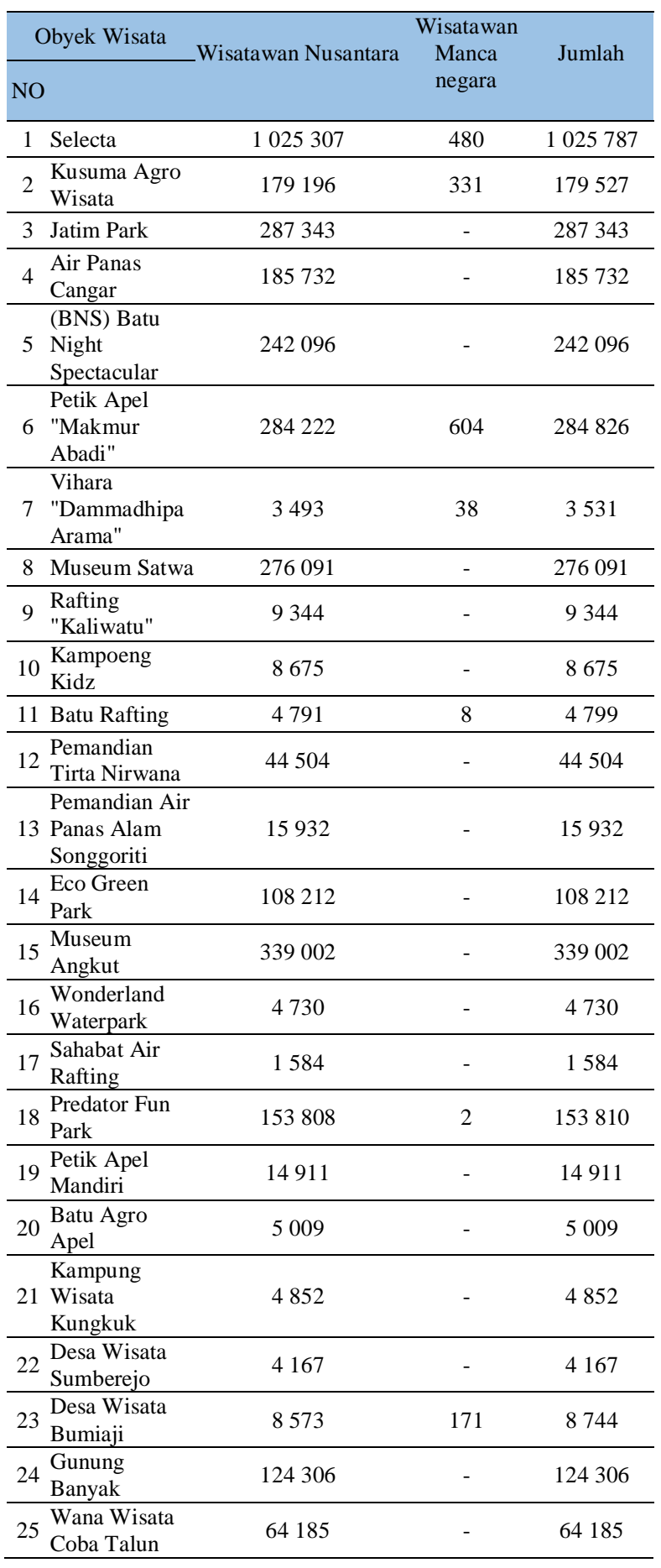




\begin{tabular}{|c|c|c|c|c|}
\hline 26 & $\begin{array}{l}\text { Wana Wisata } \\
\text { Coban Rais }\end{array}$ & 148469 & - & 148469 \\
\hline 27 & $\begin{array}{l}\text { Mega Star } \\
\text { Indonesia }\end{array}$ & 12616 & - & 12616 \\
\hline 28 & $\begin{array}{l}\text { Wisata Oleh- } \\
\text { oleh Deduwa }\end{array}$ & 25050 & - & 25050 \\
\hline 29 & $\begin{array}{l}\text { Mahajaya T- } \\
\text { Shirt \& Oleh- } \\
\text { oleh }\end{array}$ & 99025 & 326 & 99351 \\
\hline 30 & $\begin{array}{l}\text { Wisata Oleh- } \\
\text { oleh Brawijaya }\end{array}$ & 499063 & 2662 & 501725 \\
\hline & Total Ku & 4184288 & 4622 & 4188910 \\
\hline
\end{tabular}

Sumber Data : batukota.bps.go.id ${ }^{1}$

Aplikasi Aver Viewer ini bisa didapatkan dengan cara download melalui smartphone masing-masing pengguna di google playstore. Dalam aplikasi ini terdapat gambaran tentang titik-titik pemantaun lalu lintas melalui CCTV yang telah dipasang di 12 titik rawan kemacetan. Dengan adanya aplikasi ini pengguna dapat melihat kondisi lalu lintas di Kota Batu tanpa harus datang langsung ke lapangan atau tempat kejadian. Sebelum menggunakan aplikasi Aver Viewer ini masyarakat hanya perlu registrasi dan mengikuti petunjuknya saja. Setelah registrasi dan aktif, akan muncul angka yang menunjukkan CCTV di setiap titiknya. Pantauan dalam aplikasi Aver Viewer ini berlangsung secara real time selama 24 jam.

Dalam penelitian ini berfokus kepada Efektivitas Aver Viewer dalam memantau kemacetan di Kota Batu. Menurut (Wijoyo 2007: 137) efektivitas merupakan suatu kegiatan yang dilakukan dan memiliki

https://batukota.bps.go.id/statictable/2019/01 /08/366/jumlah-kunjungan-wisatawanmenurut-tempat-wisata-dan-wisata-oleholeh-di-kota-batu-2017.html dampak serta hasil yang sesuai dengan apa yang telah diharapkan. Efektivitas juga dapat diartikan sebagai pengukuran keberhasilan dalam pencapaian tujuan-tujuan yang telah ditentukan. Pengukuran efektivitas dapat dilakukan dengan cara melihat hasil kerja yang telah dicapai oleh suatu organisasi. Efektivitas ini dapat diukur melalui berhasil atau tidaknya suatu organisasi mencapai tujuantujuannya. Apabila suatu organisasi mencapai sebuah tujuannya, maka organisasi tersebut dapat dikatakan berjalan dengan efektif. Menurut Richard dan M. Steers tolak ukur efektivitas antara lain :
a. Kemampuan menyesuaikan diri
b. Prestasi kerja
c. Kepuasan kerja
d. Kualitas
e. Penilaian oleh pihak luar

Sedangkan menurut Duncan yang telah dikutip oleh Richards $M$. Steers dalam bukunya "Efektivitas Organisasi" menyatakan mengenai tolak ukur efektivitas sebagai berikut.
a. Pencapaian tujuan
b. Intergrasi
c. Adaptasi

Tetapi pada kenyataannya, aplikasi Aver Viewer masih jarang diketahui oleh wisatawan ataupun masyarakat Kota Batu itu sendiri. Dalam penelitian ini peneliti bertujuan untuk mengetahui efektifitas Aver Viewer ini. Seberapa 
besar tingkat partisipasi masyarakat Batu sendiri dalam menanggapi aplikasi yang di ciptakan. Banyak hal yang perlu di garis bawahi dan menjadi fokus bagi pemerintahan dalam menciptakan pelayanan yang berbasis teknologi, yang mana menjadi suatu harapan tersendiri agar pelayanan yang dijalankan bisa Jenis dalam penelitian ini adalah penelitian deskriptif dengan menggunakan pendekatan kualitatif. Metode penelitian deskriptif Menurut (Sugiyono 2005: 21) adalah suatu metode yang digunakan untuk menggambarkan atau menganalisis suatu hasil penelitian tetapi tidak digunakan untuk membuat kesimpulan yang lebih luas. Metode penelitian deskriptif ini salah satu metode penelitian yang banyak digunakan pada penelitian yang memiliki tujuan untuk menjelaskan suatu fenomena. Metode penelitian deskriptif merupakan sebuah metode yang digunakan untuk mendeskripsikan,

menginterprestasikan suatu fenomena seperti kondisi atau hubungan yang ada, pendapat yang berkembang, dengan mengguakan prosedur iliah untuk menjawab masalah secara aktual.

Teknik pengumpulan data yang oleh peneliti adalah wawancara kepada staf Dinas Perhubungan Kota Batu dan masyarakat Kota Batu yang

\section{HASIL DAN PEMBAHASAN}

Dinas Perhubungan Kota Batu merupakan unsur pelaksana Pemerintah Daerah untuk mencapai tujuannya yaitu lebih mudah lagi bagi pengguna. Pelayanan berbasis teknologi atau yang biasa disebut dengan $E$ Government ini menciptakan berbagai perubahan utamanya pada reformasi birokrasi.

\section{METODE PENELITIAN}

memiliki kriteria sesuai dengan kebutuhan dengan terjun langsung ke lapangan (observasi). Selain itu, peneliti juga menyebarkan angket kepada masyarakat untuk mengetahui tingkat keefektifan aplikasi Aver Viewer dalam memantau kemacetan di Kota Batu. Angket merupakan sebuah teknik pengumpulan data yang dilakukan dengan cara memberikan beberapa pertanyaan tertulis kepada subjek penelitiam terkait dengan topik yang akan dibahas.

Analisis data adalah proses untuk mencari dan menyusun data secara sistematis yang diperoleh dari hasil pengamatan, wawancara, catatan lapangan, dan studi dokumentasi. Adapun teknik analisis data di penelitian ini dilakukan dalam tiga tahapan yaitu reduksi data, penyajian data, dan penarikan kesimpulan. Fokus dalam penelitian ini adalah untuk mengetahui efektivitas penggunakan aplikasi aver viewer dalam memantau kemacetan di Kota Batu. merumuskan kebijakan teknis di bidang perhubungan, melaksanakan tugas operasional dalam bidang perhubungan seperti teknis lalu lintas 
dan parkir, teknis angkutan dan terminal, teknis saran dan operasional berdasarkan peraturan perundang-undangan yang berlaku. Hal tersebut berdasarkan Peraturan Daerah Kota Batu No. 5 Tahun 2016 tentang Pembentukan dan Susunan Perangkat Daerah dan Peraturan Walikota Batu No. 82 Tahun 2016 tentang Kedudukan, Susunan Organisasi, Uraian Tugas dan Fungsi, Serta Tata Kerja Dinas Perhubungan Kota Batu. Sesuai dengan Perauturan Walikota Batu Nomor 82 Tahun 2016 tentang Kedudukan, Susunan Organisasi, Uraian Tugas dan Fungsi, Serta Tata Kerja Dinas Perhubungan Kota Batu dalam BAB III Uraian Tugas dan Fungsi Bagian Kedua Bidang Lalu Lintas Pasal 6 Ayat 1 Dinas Perhubungan Kota Batu mempunyai tugas dalam Bidang Lalu Lintas yaitu untuk merumuskan dan melaksanakan kebijakan teknis di bidang manajemen dan rekayasa lalu lintas serta pembinaan keselamatan. ${ }^{2}$

Berpedoman pada Visi dan

Misi Walikota Kota Batu yang diimpelmentasikan dalam Visi Kota Batu yaitu "Desa Berdaya Kota Berjaya: Terwujudnya Kota Batu sebagai Sentra Agrowisata Internasional yang Berkarakter, Berdayasaing dan Sejahtera" Dinas Perhubungan ikut serta dalam mensukseskan visi tersebut dengan

2

https://ppid.batukota.go.id/profil/visi_misi_ walikota

https://jdih.batukota.go.id/peraturanwalikota-batu-nomor-82-tahun-2016-html cara mewujudkan tata kelola transportasi Kota Batu yang aman dan nyaman guna membantu mensejahterakan masyarakat. Selain itu untuk mendukung terwujudnya salah satu misi Walikota Kota Batu yaitu "Meningkatkan Tata Kelola Pemerintahan yang Baik, Bersih, dan Akuntabel Berorientasi pada Pelayanan Publik yang Profesional" maka Dinas Perhubungan Kota Batu membuat inovasi layanan publik yaitu Aver Viewer.

Sebagai salah satu kota wisata yang terkenal di Indonesia, tak jarang Kota Batu sering mengalami kecametan saat waktu liburan tiba. Titik-titik yang sering megalami tingkat kemacetan yang sangat parah saat liburan tiba adalah di Jl. Ir. Soekarno Desa Beji Kecamatan Junrejo (depan Jawa Timur Park 3), Jl. Terusan Sultan Agung Kelurahan Ngaglik Kecamatan Batu (depan Museum Angkut), dan Jl. Arumdalu Kelurahan Songgoketto Kecamatan Batu. Hal ini lah yang membuat Dinas Perhubungan Kota Batu untuk terus berinovasi untuk memberikan pelayanan. Dalam pelayanan publik sangat diperlukan adanya inovasi, karena dengan adanya inovasi pelayanan publik selain untuk mewujudkan good governance juga dapat memudahkan masyarakat dalam mendapatkan pelayanan yang diberikan oleh pemerintah. Dengan adanya aplikasi aver viewer ini diharapkan mampu untuk memberikan kemudahan kepada 
masyarakat maupun dalam melihat titik-titik kemacetan lalu lintas yang terjadi di Kota Batu.

Aplikasi Aver Viewer merupakan aplikasi yang diluncurkan pada tahun 2013 oleh Dinas Perhubungan Kota Batu untuk melakukan pemantauan kemacetan lalu lintas di Kota Batu. Aplikasi ini sangat bermanfaat bagi masyarakat maupun wisatawan untuk menghindari kemacetan. Dengan aplikasi ini pengguna bisa memantau titik macet lalu lintas melalui smartphone dan dapat mencari solusi untuk menghadapi kemacetan. Pantauan CCTV inipun dilakukan secara real time selama 24 jam penuh. Dalam aplikasi Aver Viewer terbagi menjadi dua pantauan kamera CCTV, yaitu DVR 1 ada 10 kamera dan DVR 2 ada 11 kamera. Adapun letak titik-titik pemasangan CCTV tersebut sebagai berikut.

Tabel 2. Titik-titik Pemasangan CCTV DVR 1 dalam Aplikasi Aver Viewer

\begin{tabular}{|l|}
\hline \multicolumn{2}{|c|}{ DVR 1 } \\
\hline $\begin{array}{l}\text { Kamera } 1 \text { dan } 2 \text { di Perempatan } \\
\text { Arhanud }\end{array}$ \\
\hline $\begin{array}{l}\text { Kamera } 3 \text { dan } 4 \text { di Pertigaan } \\
\text { Pendem }\end{array}$ \\
\hline Kamera di 5 di Jatim Park 2 \\
\hline $\begin{array}{l}\text { Kamera } 6 \text { dan } 7 \text { di Persimpangan } \\
\text { lima Desa Junrejo }\end{array}$ \\
\hline $\begin{array}{l}\text { Kamera } 8 \text { dan 9 di Pertigaan Dewi } \\
\text { Sartika bawah arah ke Pasar Batu }\end{array}$ \\
\hline Kamera 10 di Dewi Sartika atas \\
\hline Sumber Data : Suryamalang.com \\
Tabel 3. Titik-titik Pemasangan \\
CCTV DVR 2 dalam Aplikasi Aver \\
Viewer
\end{tabular}

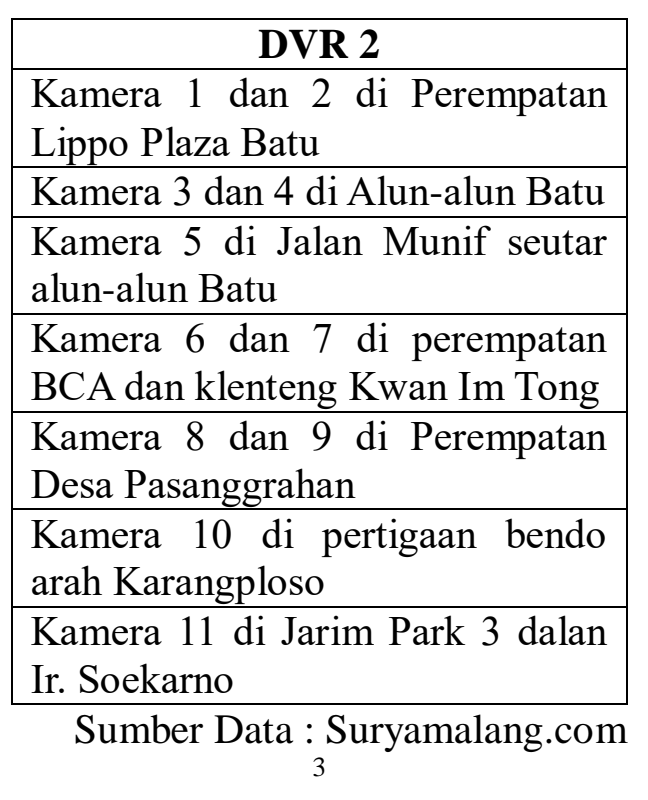

Aplikasi Aver Viewer ini dapat digunakan oleh siapa saja melalui smartphone dengan cara mendownloadnya di playstore. Berikut cara-cara yang dapat dilakukan untuk mengakses aplikasi Aver Viewer.

1. Mendownload Aplikasi Aver Viewer melalui Playstore

2. Setalah mendownload dan membuka aplikasi Aver Viewer, pengguna akan diberikan dua pilihan menu yaitu pilih dan klik DVR/NVR.

3. Klik Tombol (+) pada kolom di bawah

4. Akan muncul 5 kolom yaitu name, host, port, ID, dan password

5. Isi kolom name dengan DVR 1
3

https://www.google.co.id/amp/s/suryamalan g.tribunnews.com/amp/2019/06/07/ini-carapantau-cctv-di-sejumlah-titik-di-kotbatucatat-paswordnya 
6. Isi kolom Host dengan 114.6.72.102.

7. Isi kolom Port dengan 5550.

8. Isi kolom ID dengan admin.

9. Isi kolom Password dengan admin.

10. Klik kotak pada remember my password

11. Klik tombol save pada kotak di kanan pojok atas.

Efektivitas

merupakan

pengukuran keberhasilan dalam pencapaian tujuan-tujuan yang telah ditentukan. Jika ditinjau dari aspek efektivitas, aplikasi ini dinilai cukup efektif dalam mengatasi kemacetan di Kota Batu apalagi Kota Batu sering mengalami kemacetan saat liburan tiba. Tujuan dari adanya aplikasi Aver Viewer ini yaitu untuk memberikan informasi kepada masyarakat mengenai keadaan lalu lintas dengan cara melihat titik-titik pantau yang sudah ada aplikasi tersebut. Adanya aplikasi ini sangat membantu masyarakat untuk mencari jalur alternalif saat terjadi kemacetan karena apabila terjadi kemacetan, Dinas Perhubungan segera menggunakan teknik buka tutup jalur dan berkoordinasi langsung dengan pihak kepolisian.
Gambar 1. Tampilan Tata Letak
CCTV

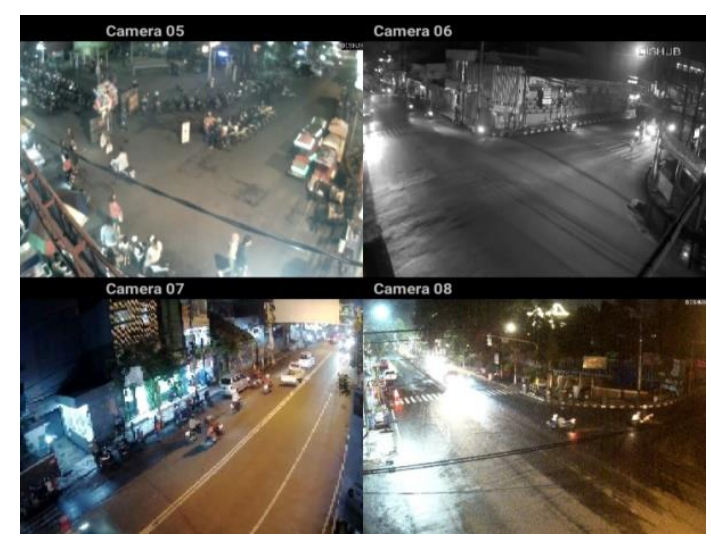

Sumber: Aplikasi Aver Viewer

Dari hasil wawancara yang dilakukan dengan Bapak Khoirul selaku staf di Dinas Perhubungan, selain untuk memantau arus lalu lintas, CCTV yang digunakan dalam aplikasi Aver Viewer ini juga dapat digunakan untuk melacak tindak kriminalitas yang ada di Kota Batu. Dinas Perhubungan Kota Batu bekerjasama dengan aparat kepolisian untuk menindaklanjuti tindak kriminalitas yang terjadi. Jika terjadi kemacetan di Kota Batu, pihak satuan lalu lintas dan Dinas Perhubungan akan langsung bekerjasama mencari jalan-jalan alternatif yang bisa dilewati untuk mengurangi kemacetan. Selain adanya tuntutan dari masyarakat, pembuatan aplikasi Aver Viewer ini merupakan inisiatif dari pihak pemerintah dan kepolisian karena dengan adanya aplikasi ini dapat mempermudah Dinas Perhubungan dan Polisi Lalu Lintas memantau kemacetan sehingga jika terjadi kemacetan dapat ditangani dengan cepat dengan cara memberikan jalur- 
jalur alternatif bagi para pengguna jalan.

Keberadaan aplikasi Aver Viewer ini bermaksud dan bertujuan untuk memberikan kemudahan dalam mengatasi kemacetan di Kota Batu. Dengan adanya aplikasi Aver Viewer ini diharapkan mampu mengurangi kemacetan yang terjadi di Kota Batu dan memberikan kemudahan untuk para pengguna jalan untuk memantau lalu lintas tanpa turun langsung ke lapangan. Hanya saja masih terdapat berbagai kendala untuk menggunakan aplikasi Aver Viewer mengingat pengguna harus terlebih dahulu mendownload serta mendaftarakn diri untuk bergabung dengan pengguna lainnya, selain itu untuk mengakses aplikasi ini sangat dibutuhkan koneksi internet yang bagus.

Namun dalam segi sosialiasi mengenai aplikasi Aver Viewer dinilai sangat kurang, karena masih banyak masyarakat Kota Batu maupun Luar Kota Batu yang belum mengetahui adanya aplikasi ini. Dari hasil survei yang dilakukan oleh peneliti terhadap masyarakat Kota Batu maupun Luar Kota Batu, hanya sedikit masyarakat yang mengetahui adanya aplikasi ini. Kebanyakan dari mereka mengaku baru mendengar jika ada aplikasi yang bernama Aver Viewer yang digunakan untuk memantau kemacetan di Kota Batu. Banyaknya aplikasi lain yang digunakan oleh Pemerintah Kota Batu menjadi salah satu faktor penyebab kurangnya pengetahuan masyarakat terhadap aplikasi Aver Viewer, aplikasi lain tersebut seperti Among Tani, Among Warga, dan Among Kota. Tiga aplikasi tersebut merupakan aplikasi andalan di Kota Batu dan lebih dikenal oleh masyarakat luas daripada aplikasi Aver Viewer. Terlalu banyaknya aplikasi ini membuat masyarakat bingung, aplikasi apa yang seharusnya mereka gunakan. Akan lebih efektif lagi jika Pemerintah Kota Batu hanya menggunakan satu aplikasi saja, namun di dalam aplikasi tersebut tedapat pilihahpiliha menu di dalamnya salah satunya adalah Aver Viewer tersebut.

Harapannya adalah aplikasi Aver Viewer ini dapat di sosialiasaikan dengan baik dan merata agar semua masyarakat Kota Batu maupun Luar Kota Batu dapat mengetahui dan menggunakan aplikasi ini. Cara mensosialisasikan dapat berupa membuat iklan di Channel TV yang dimiliki oleh kota tersebut (Batu TV), melalui media sosial yang dimiliki oleh Dinas Perhubungan Kota Batu, memberikan sosialisasi kepada Kepala Desa yang ada di Kota Batu, nantinya Kepala Desa tersebutlah yang akan mensosialisasikan kepada warga-warga setempat. Dengan adanya sosialisasi ini akan membuat aplikasi Aver Viewer ini lebih dikenal oleh masyarakat luas dan dapat membantu masyarakat yang ingin berpergian ke Kota Batu mencari jalur-jalur alterantif agar tidak terjebak kemacetan. 
Gambar 2. Angket tau tidaknya masyarakat dengan aplikasi Aver Viewer

Apakah anda mengetahui aplikasi aver viewer yang disediakan oleh dinas perhubungan kota Batu?

10 tanggapan

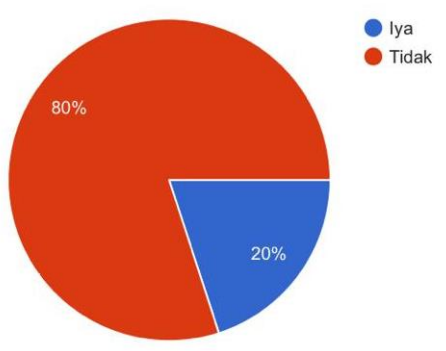

Sumber Data : Google Form yang dibuat oleh peneliti

Gambar 3. Angket asal daerah pengisi Google Form

Asal Daerah

10 tanggapan

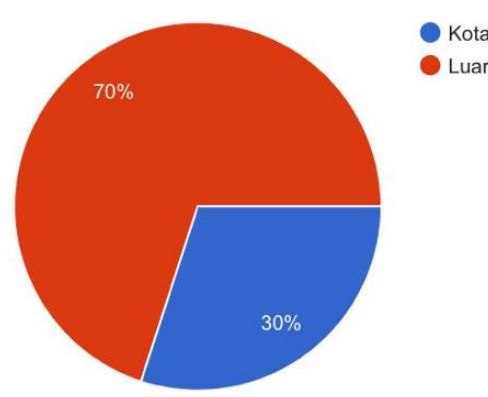

Sumber Data : Google Form yang dibuat oleh peneliti

Jika dlihat dari rating di playstore, aplikasi Aver Viewer telah di download oleh lebih dari seratus ribu unduhan, artinya sudah banyak masyarakat umum yang menggunakan aplikasi ini. Masyarakat juga memberikan nilainilai yang cukup variatif sesuai dengan kenyamanan mereka terhadap aplikasi ini. Dilihat dari rating antara masyarakat yang memebri bintang satu dan lima hampir sama jumlahnya. Dari banyaknya bintang lima yang diberikan, para pengguna mungkin sangat puas dengan adanya aplikasi ini. Meski begitu, kritik dan saran yang diberikan oleh para pengguna harus di respon juga, karena hal tersebut dapat dijadikan patokan dalam melakukan evaluasi terhadap aplikasi Aver Viewer ini.

Gambar 4. Rating dan Ulasan Aplikasi Aver Viewer

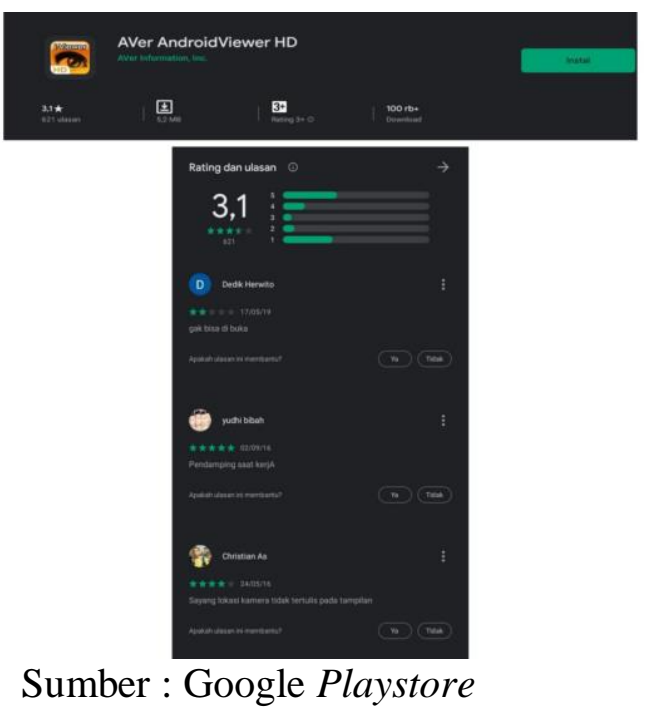

Dalam menerapkan aplikasi Aver Viewer ini, Dinas Perhubungan memiliki kendala dalam pelaksanaannya, kendala tersebut antara lain:

1. Letak geografis Kota Batu yang berbeda. Hal tersebut mengakibatkan pemasangan Wi-fi yang terhubung ke kamera CCTV tidak maksimal.

2. Adanya tangan-tangan jahil oknum yang tidak bertanggungjawab merusak 
kamera di titik-titik terpasangnya CCTV sehingga mengakibatkan CCTV tersebut rusak.

3. Pemantauan CCTV yang bebas di akses masyarakat, menyebabkan hacker ikut melakukan kejahilannya. Bapak Khoirul selaku staf di Dinas Perhububungan mengatakan pernah terjadi arah kamera CCTV 360 dibolak-balik oleh mereka yang pandai dalam IT.

4. Terjadinya bencana alam seperti angin puting beliung yang pernah terjadi di Kota Batu yang mengakibatkan rusaknya beberapa kamera CCTV.

\section{KESIMPULAN DAN SARAN}

\section{Aplikasi Aver Viewer ini} digunakan untuk memantau kemacetan lalu lintas di Kota Batu. Aplikasi Aver Viewer dapat di download pada google playstore dengan cara login terlebih dahulu ke dalam aplikasi tersebut. Selain adanya tuntutan dari masyarakat, pembuatan aplikasi Aver Viewer ini merupakan inisiatif dari pihak pemerintah dan kepolisian karena dengan adanya aplikasi ini dapat mempermudah Dinas Perhubungan dan Polisi Lalu Lintas memantau kemacetan sehingga jika terjadi kemacetan dapat ditangani dengan cepat dengan cara memberikan jalurjalur alternatif bagi para pengguna jalan.

Adanya aplikasi Aver Viewer ini dinilai cukup efektif, karena dengan adanya aplikasi ini mempermudah masyarakat maupun wisatawan yang ingin berpergian ke Kota Batu untuk melihat keadaan lalu lintas di Kota Batu tanpa harus datang langsung ke lapangan. Namun sosialisasi yang dilakukan Dinas Perhubungan Kota Batu dinilai kurang, karena masih banyak masyarakat Kota Batu maupun Luar Kota Batu yang mengetahui adanya aplikasi Aver Viewer ini. Harapannya adalah aplikasi Aver Viewer ini dapat di sosialiasaikan dengan baik dan merata agar semua masyarakat Kota Batu maupun Luar Kota Batu dapat mengetahui dan menggunakan aplikasi ini. Cara mensosialisasikan dapat berupa membuat iklan di Channel TV yang dimiliki oleh kota tersebut (Batu TV), melalui media sosial yang dimiliki oleh Dinas Perhubungan Kota Batu, memberikan sosialisasi kepada Kepala Desa yang ada di Kota Batu, nantinya Kepala Desa tersebutlah yang akan mensosialisasikan kepada warga-warga setempat. Dengan adanya sosialisasi ini akan membuat aplikasi Aver Viewer ini lebih dikenal oleh masyarakat luas dan dapat membantu masyarakat yang ingin berpergian ke Kota Batu mencari jalur-jalur alterantif agar tidak terjebak kemacetan. Jika dilihat dari rating di google playstore, aplikasi Aver Viewer sudah di download oleh lebih dari seratus ribu pengguna yang masing-masing pengguna memiliki penilaian yang berbeda-beda. 
DAFTAR PUSTAKA

[1] Harahap, Erwi. Dkk "EFEKTIFITAS LOAD

BALANCING DALAM MENGATASI KEMACETAN

LALU LINTAS". Jurnal Matematika. Vol 1, No 2. 2017

[2] Nofli K Staal, Steven R Sentinuwo, Alwin M Sambul. 2017. Rancang Bangun Aplikasi Pemantauan Trafik Lalu Lintas Menggunakan GPS Smartphone. Jurnal Teknik Informatika, Volume 13, No. 1. Universitas Ratulangi Manado.

[3] Hardiansyah. 2020. Deteksi Perjalanan Kendaraan Untuk Mengukur Kepadatan Lalu Lintas Menggunakan Menggunakan OpenCV Python. Jurnal Ilu Komputer JIK, Volume 3, No. 2. STMIK Eresha.

[4] Nurhayati Buslim, Busman Busman, Nadika Sigit Sinatrya, Tifani Shallynda Kania. 2018. Analisa Sentimen Menggunakan Data Twitter, Flume, Hive Pada Hadoop dan Java Untuk Deteksi Kemacetan di Jakarta. Jurnal Online Informatika, Volume 3, No.1
[5] Kholilatul Wardani, Aditya Kurniawan. 2016. Pemantauan Kondisi Kepadatan Jalan Kelurahan Sawojajar dengan menggunakan Image Processing Berbasis Visual Basic 6.0. TELKA-Telekomunikasi,

Elektronika, Komputasi dan Kontrol, Volume 2, No.1

[6] Luthfiana Putri Aisyah, Eko Priyo Purnomo, Aulia Nur Kasiwi, 2020. Efektivitas Konstruksi Jembatan Layang Sebagai Penguraian Kemacetan dalam Kerangka Smart Mobility di Kota Yogyakarta Tahun 2019 (Studi Kasus Jembatan Layang (Fly Over) Janti). Gorontalo Journal of Government and Political Studies, Volume 3 No.1 